\title{
Evaluating Loop Heat Pipes Performances Regarding Their Geometric Characteristics
}

\author{
Roger R. Riehl \\ National Institute for Space Research - INPE/DMC \\ Tulio C. P. A. Siqueira \\ Universidade Federal de Ouro Preto - DECA
}

Copyright $\odot 2005$ SAE International

\begin{abstract}
This paper presents the performance tests of small-scale loop heat pipes (LHPs) that have being developed in order to perform the heat dissipation using acetone as working fluid. Two LHPs have being designed and built to accomplish the thermal management on power cycles of up to $80 \mathrm{~W}$, where each LHP has a different set of compensation chamber/capillary evaporator, being one detached from the evaporator while the other is an integral part of it. Laboratory life tests have shown reliable operation with negligible non-condensable gas influence along time. The basic difference between tests with both LHPs is that the one with an integral compensation chamber showed higher operation temperatures due to the smaller thermal resistances between the evaporator and the compensation chamber. The life tests results show the potential in using acetone as an alternative working fluid in LHPs with reduced active lengths.
\end{abstract}

\section{INTRODUCTION}

The loop heat pipe (LHP) technology has been under development in this institute for future space applications, concerning specific thermal dissipation levels to be managed in current scientific and observation satellites that are under development. The application of heat pipes in space radiators that have been used will eventually face some limits so LHPs must be then considered. As the qualification of LHPs demand a long term investigation and development, several steps have been made to qualify these devices for future space applications using alternative working fluids.

The development of this technology has been focused on small-scale LHPs, designed to perform the thermal management of up to $80 \mathrm{~W}$ on power cycles using acetone as the working fluid. The intention of substituting the so-used ammonia is related to reduce the hazard during the working fluid manipulation, as well as reducing distillation/charging costs with this fluid.
Small-scale LHPs have been investigated to be used in space applications [1] showing great potential in applying them on the thermal control. On the same way, alternative working fluids have been also investigated and employed $[2,3]$ showing that acetone can promote a reliable thermal management for low power LHPs. However, due to the lack of extensive informations regarding the qualification of acetone as a potential working fluid for future space applications, an investigation in this matter becomes necessary.

Another subject that has to be carefully considered is the proper compensation chamber configuration that the LHP must have. In regular cylindrical capillary evaporators, the compensation chamber is part of the evaporator itself as these two components represent a single set. In this case, the compensation chamber configuration is important, which can be an integral part of the evaporator (with the same outer diameter) [4] or can be detached from the evaporator body $[5,6]$. The compensation chamber (CC) configuration geometry must be carefully selected, specially when the heat leak from the capillary evaporator is a concern as well as integration issues in the satellite.

Focusing on the requirements for developing small-scale LHPs able to manage the heat dissipation needs in future applications, this paper presents the results of the investigation of two LHPs. The LHPs were designed, built and have been under test during the past 20 months using acetone as the working fluid, in order to gather the required informations to refine the project and qualify them for future applications. The comparison between the two LHPs are important to evaluate the influence of the $\mathrm{CC}$ on their thermal performance along time, as each of them present different CCs.

\section{LOOP HEAT PIPES DEVELOPMENT}

For the above-mentioned criteria that has been imposed to the current project, a long-term LHP technology development has been undergoing in order to qualify this 
device for future applications. Life tests using acetone as the working fluid are necessary to better determine the issues related to the use of this fluid, specially related to the non-condensable gases (NCGs) influence.

The current development of the small-scale LHPs have been focused on regular cylindrical capillary evaporators/CCs. However, reversible, ramified and mini-LHPs have also been under development along with pulsating heat pipes (configured on both close and open loops). Even though the results presented in this paper are related to capillary evaporators using UHMW polyethylene as primary wicks, there has been an extensive investigation with other wicks made of sintered nickel and ceramics. Polyethylene wicks have been successfully used previously [7] and have also been used in CPLs aboard the Terra Spacecraft [8].

For this investigation, two LHPs were designed and built to perform the thermal management of up to $100 \mathrm{~W}$, for sink temperature of $0{ }^{\circ} \mathrm{C}$ and maximum evaporator temperature of $120^{\circ} \mathrm{C}$. However, they should operate in power cycles up to a maximum of $80 \mathrm{~W}$. The LHPs differ from each other on the CC geometric characteristics as this component is very important to the proper operation of these devices. In this case, as both LHPs are identical in all aspects, a comparison between each other becomes interesting to better evaluate the CC influence on the overall thermal performance of low power LHPs.

The LHPs were built according to the characteristics presented by Table 1, using 316L stainless steel on the entire setups and aluminum (alloy 6061) on the capillary evaporators saddles $(70 \times 45 \mathrm{~mm})$ and condensation plates $(300 \times 300 \mathrm{~mm} \times 4 \mathrm{~mm}$ thick). The devices, treated as Thermal Control Devices (TCD), were named as TCD-LHP and TCD-LHP2 as presented by Fig 1.

Table 1. Geometric characteristics of the LHPs under tests.

\begin{tabular}{|c|c|c|c|}
\hline \multicolumn{2}{|l|}{ Capillary Evaporator } & \multicolumn{2}{|l|}{ Liquid Line } \\
\hline Total Length (mm) & 100 & Outer Diam eter (mm) & 4.85 \\
\hline Active L ength (mm) & 67 & Inner Diameter (mm) & 2.85 \\
\hline Outer/Inner Diam eter $(\mathrm{mm})$ & $19.0 / 16.5$ & Length $(\mathrm{mm})$ & 850 \\
\hline Material & $\begin{array}{l}\text { Stainless steel grade } \\
\text { 316L (ASTM) }\end{array}$ & Material & $\begin{array}{l}\text { Stainless steel grade } \\
316 \mathrm{~L} \text { (ASTM) }\end{array}$ \\
\hline UHMW Polyethylene Wich & & Condenser & \\
\hline Pore Radius $(\mu \mathrm{m})$ & 6 & Outer Diam eter (mm) & 4.85 \\
\hline Permeability $\left(\mathrm{m}^{1}\right)$ & $10^{-13}$ & Imer Diameter (mm) & 2.85 \\
\hline Porosity (\%) & 50 & Length $(\mathrm{mm})$ & 1000 \\
\hline Diameter (OD/ID) mm & $16.5 / 7.0$ & Material & $\begin{array}{l}\text { Stainless steel grade } \\
\text { 316L (ASTM) }\end{array}$ \\
\hline Grooves height, width, angle & $2.0 \mathrm{~mm} / 2.5 \mathrm{~mm} / 26^{\circ}$ & & \\
\hline Number of Grooves & 15 & & \\
\hline Compensation Chamber & & Vopor Line & \\
\hline Volume $\left(\mathrm{cm}^{3}\right)$ & 20 & Outer Diam eter (mm) & 4.85 \\
\hline Screen mesh & $\begin{array}{l}\# 200 \text { Stainless steel } \\
\text { grade 304L (ASTM) }\end{array}$ & Inner Diameter (mm) & 2.85 \\
\hline TCD-L HP OD/length (mm) & $45 / 25$ & Length $(\mathrm{mm})$ & 550 \\
\hline TCD-LHP2 ODAength (m m) & $19 / 95$ & Material & $\begin{array}{l}\text { Stainless steel grade } \\
\text { 316L (ASTM) }\end{array}$ \\
\hline Material & $\begin{array}{l}\text { Stainless steel grade } \\
\text { 316L (ASTM) }\end{array}$ & & \\
\hline
\end{tabular}

The condensation plate was composed of a heat exchanger with embedded channels, circulating a mixture of $50 \%$ water and $50 \%$ ethylene-glycol at a rate of $9 \mathrm{~L} / \mathrm{min}$. The condensation (sink) temperatures used to test both LHPs were $5{ }^{\circ} \mathrm{C}$ and $0{ }^{\circ} \mathrm{C}$ for all heat loads tested. The heat loads were performed using a kapton skin heater attached to each capillary evaporator saddle (70 x $15 \mathrm{~mm}, 14$ Ohms), connected to a DC power supply with deviation of $\pm 1.0 \%$. All tests were performed without pre-conditioning procedures prior the startups and without temperature control of the CC. The liquid inventory in both LHPs was 25 grams of high grade acetone, which was twice distilled and out-gassed, keeping the CCs with $50 \%$ of void fraction in the cold mode. Each LHP was instrumented with 20 type-T thermocouples (deviation of $\pm 0.3^{\circ} \mathrm{C}$ at $100{ }^{\circ} \mathrm{C}$ ) connected to a Agilent 32920A data acquisition system used to monitor the temperatures and save them on a spreadsheet file.

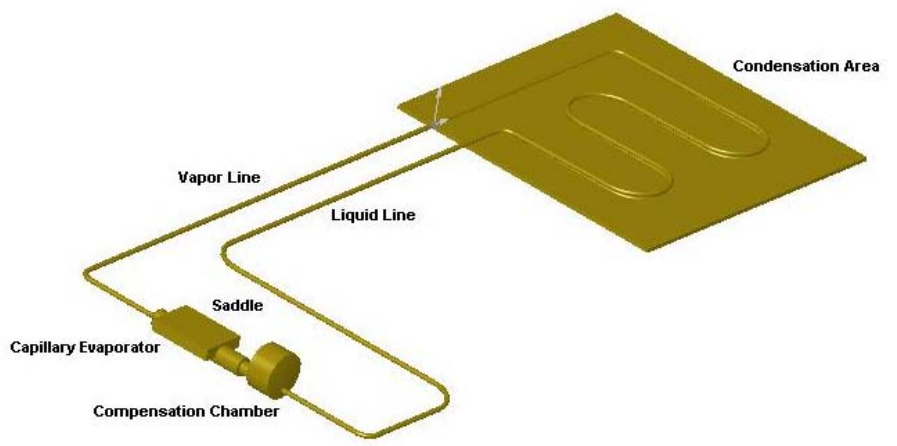

TCD-LHP

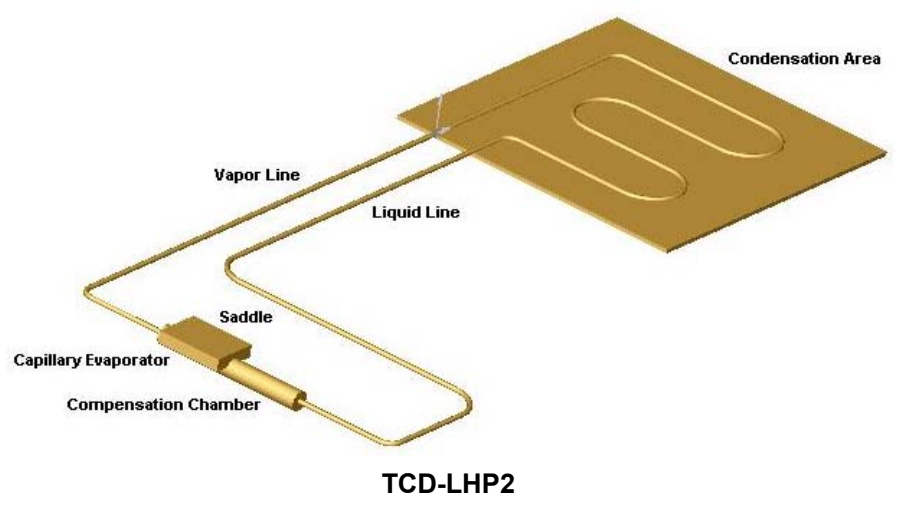

Figure 1. Representation of the small-scale LHPs.

The LHPs were tested in laboratory conditions on horizontal orientation, with a room temperature controlled between 18 and $20^{\circ} \mathrm{C}$, on power cycle test profiles as presented by Table 2. Each profile test sequence was tested with each LHP at a time and after finishing the tests, the other LHP was then tested. Such a procedure was performed repetitively in order to evaluate any difference on the LHPs thermal performance over the time caused by NCG influence. Tests were carried out during the past 20 months and present the results of 
both LHPs performance, with attention to the possible effect of NCG influence on their operation along time.

Table 2. Power cycles applied to test the LHPs.

\begin{tabular}{ccc}
\hline Profile & Power Cycle (W) & Startup Power (W) \\
\hline 1 & $20-2-30-2-40$ & 20 \\
2 & $40-10-60-5-20-80$ & 40 \\
3 & $2-10-2-30-50-2$ & 2 \\
4 & $60-5-80-2-40-10$ & 60 \\
5 & $2-5-1-2-1-5$ & 2 \\
\hline
\end{tabular}

The power cycle tests were selected according to potential LHPs operation modes. In this test sequence, an important attention is given to profile 5 were reduced heat loads are applied to the capillary evaporator of each LHP in order to evaluate their capability in promoting the heat transport in the sleeping mode. This entire test sequence, performed with both LHPs, is important to analyze the devices' operation along the life tests, promote potential design improvements and better evaluate the use of acetone as the working fluid.

Designing both LHPs with the above-mentioned geometric characteristics give a power management of up to $100 \mathrm{~W}$ using acetone as the working fluid. The maximum power management that the LHPs can accomplish can be increased by substituting the working fluid by the so-used ammonia. However, as the entire research/development program has been performed to qualify an alternative working fluid for future space applications, all efforts have been concentrated to accomplish this objective.

\section{RESULTS AND DISCUSSIONS}

The experimental results for both LHPs present acceptable behavior over the time that the life tests have been performed. Tests with the LHPs on a power step mode are presented by Figs. 2 and 3 for a sink temperature of $0^{\circ} \mathrm{C}$. TCD-LHP and TCD-LHP2 have presented reliable operation with temperatures within what it was predicted during their design and simulation.

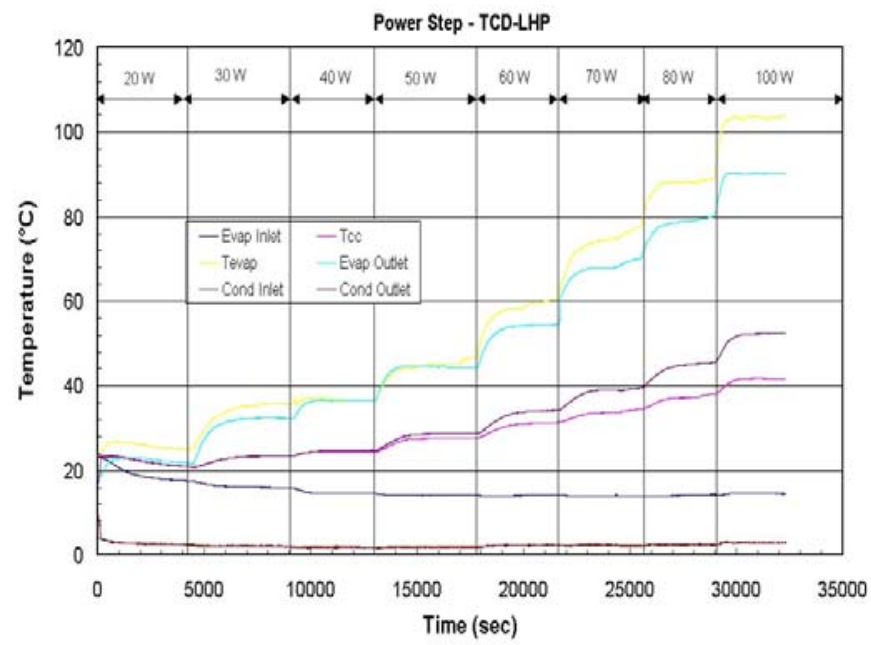

Figure 2. Power step for the TCD-LHP - sink at $0^{\circ} \mathrm{C}$.

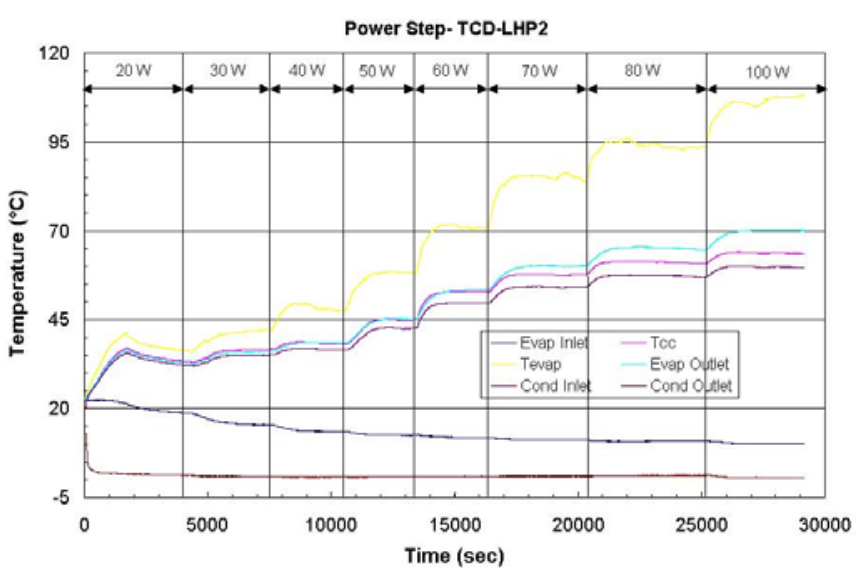

Figure 3. Power step for the TCD-LHP2 - sink at $0^{\circ} \mathrm{C}$.

Even using a primary wick made of polyethylene, the thermal management has been considerably good without any indication of temperature overshooting or evaporator dryout. Acetone has shown to be an interesting option as an alternative for ammonia for the heat load range applied in all tests. Tests with TCD-LHP present reliable startups and continuous operation during the entire test program. Every power cycle applied to the device was properly managed at both sink temperature. However, when the heat applied to the capillary evaporator was changed from a low to a high power, there were indications of cold shocks [9], which will be better discussed in a future report, as showed by Figs. 4 and 5 for tests at $5{ }^{\circ} \mathrm{C}$ and $0^{\circ} \mathrm{C}$ respectively.
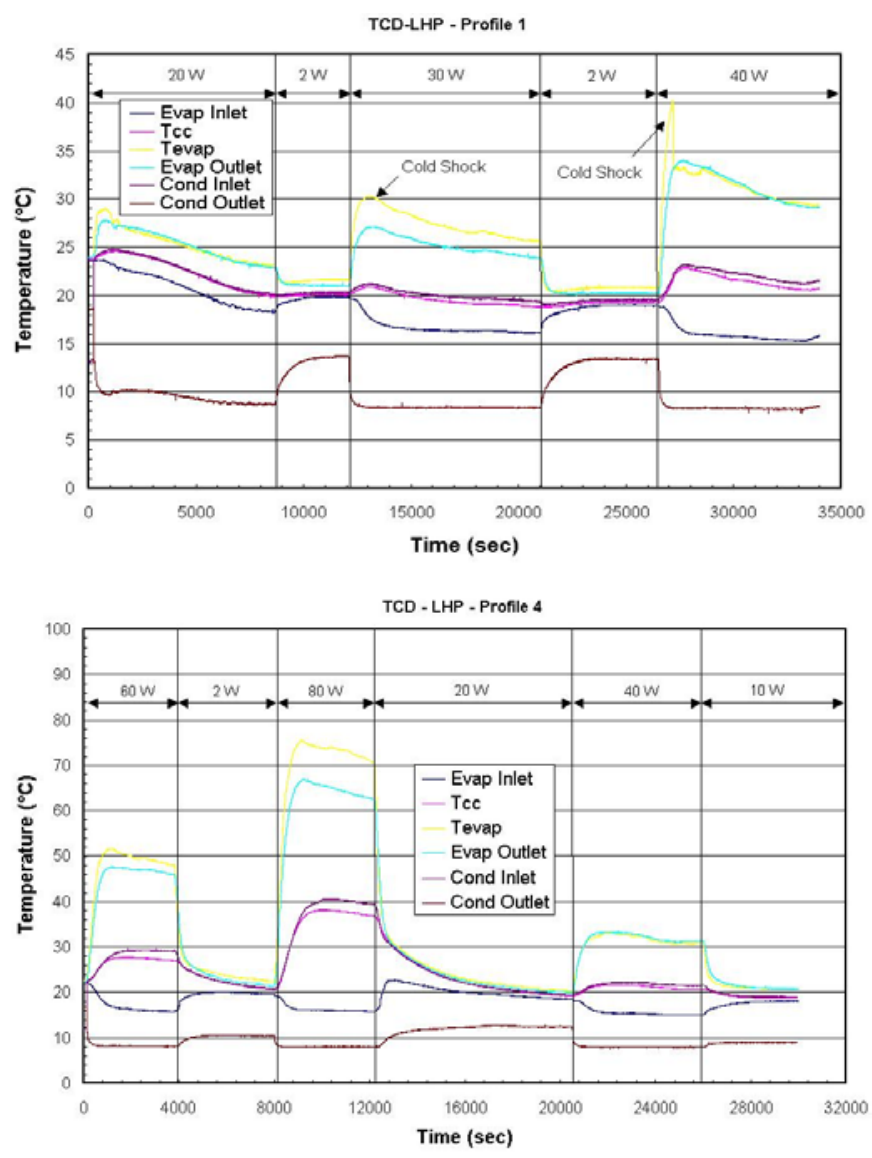

Figure 4. Power cycles for TCD-LHP - sink at $5^{\circ} \mathrm{C}$. 
At low power levels, the TCD-LHP presented continuous operation and constant heat transport even at $1 \mathrm{~W}$ when the LHP had to operate in sleeping mode (profile 5) as showed by Figs. 6 and 7 . Few oscillations were observed, which are mainly due to the reduced flow rates specially at $1 \mathrm{~W}$.
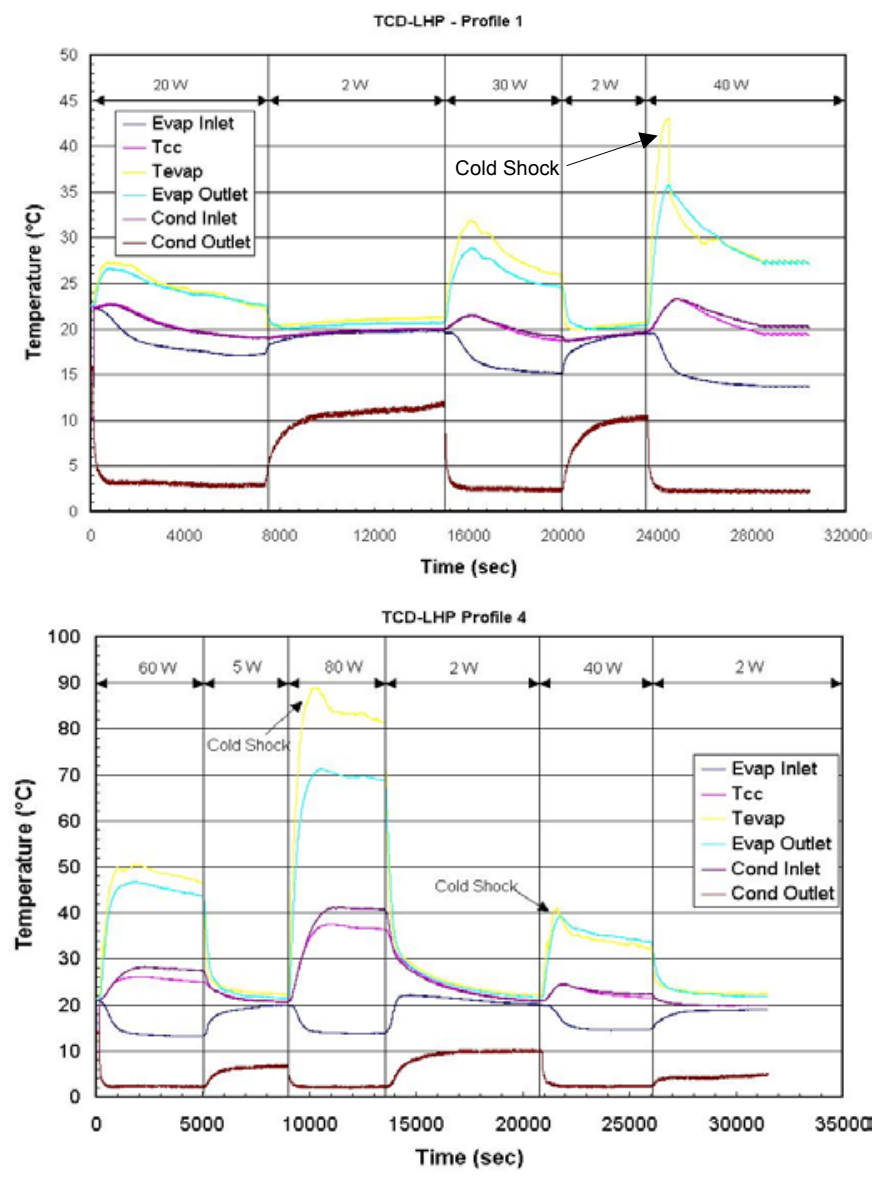

Figure 5. Power cycles for TCD-LHP - sink at $0^{\circ} \mathrm{C}$.

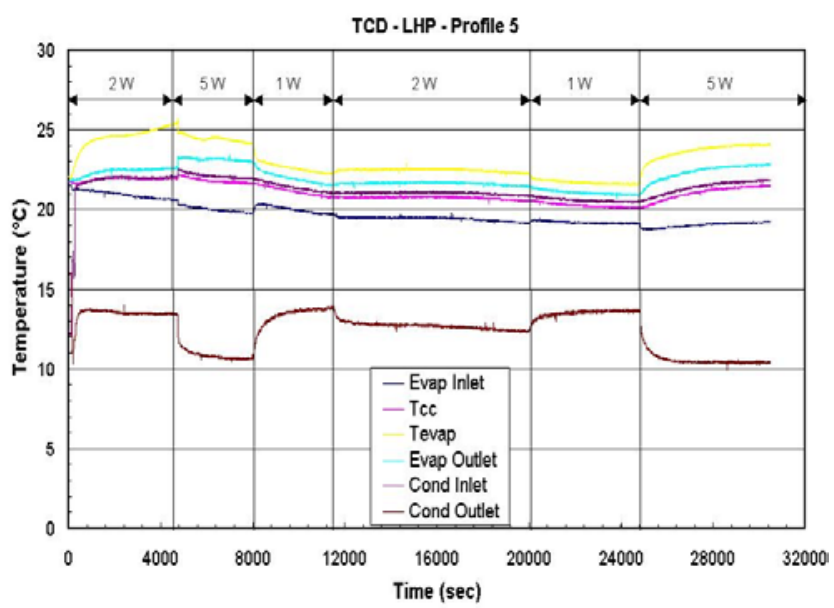

Figure 6. Sleeping mode operation - TCD-LHP and sink at $5^{\circ} \mathrm{C}$.

The overall results for the capillary evaporator temperatures are presented by Fig. 8 for both sink temperatures tested, where the characteristic U-shape curves for the capillary evaporator temperatures are presented. The TCD-LHP accomplished the entire test program with acceptable results, which were all in agreement along time without NCG influence, as the temperatures changes were always within the thermocouples deviation. Even though no influence of NCGs have been verified so far, investigations on this matter are still required.

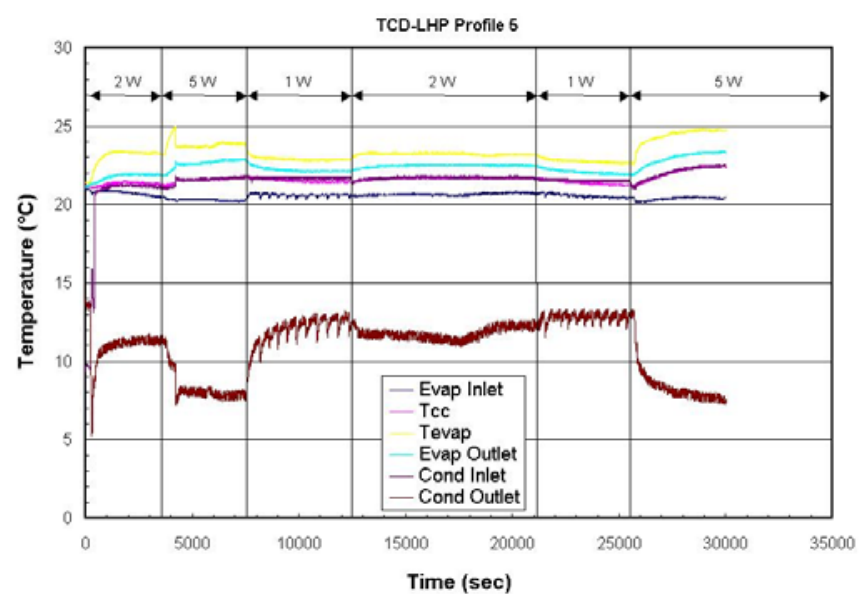

Figure 7. Sleeping mode operation - TCD-LHP and sink at $0^{\circ} \mathrm{C}$.

Evaporator Temperature Slope - TCD-LHP

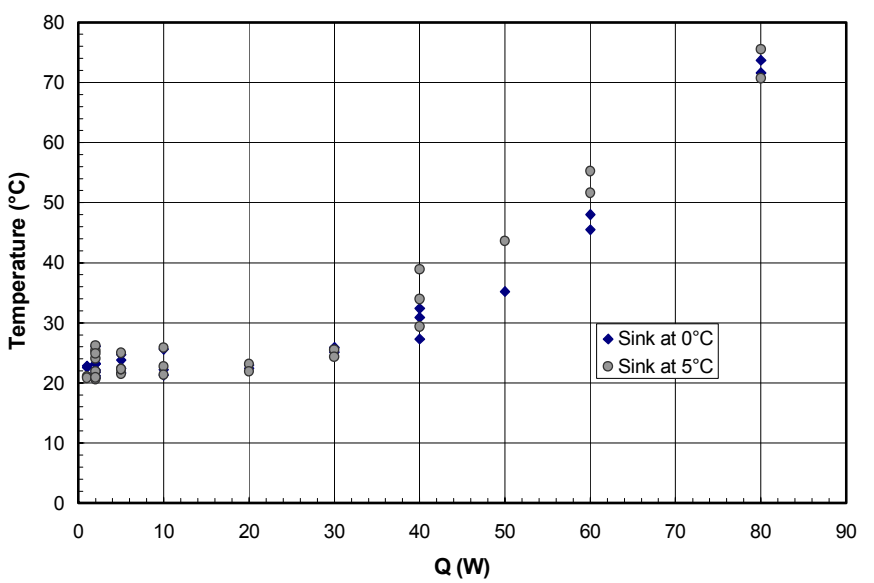

Figure 8. Overall evaporator temperatures for TCD-LHP.

Tests with TCD-LHP2 showed the same thermal management capability but the evaporator and operation temperatures were higher then those verified with TCDLHP. As the set capillary evaporator/CC has the same outer diameters and the $\mathrm{CC}$ is part of the evaporator, reduced thermal resistances are present. On the same way, as more vapor is present in the capillary evaporator, there is an increase on the heat leak (heat transfer from the evaporator to the CC) than with the TCD-LHP configuration. This increase on the evaporator temperature is directly related to the increase of the CC temperature, which affects the temperature distribution throughout the TCD-LHP2. Thus, higher temperatures are verified for all heat loads applied to the evaporator. However, the TCD-LHP2 always presented reliable operation and no indication of temperature overshoot or evaporator dryout. Figures 9 and 10 show the 
experimental results for the TCD-LHP2 with sink temperatures of $5^{\circ} \mathrm{C}$ and $0{ }^{\circ} \mathrm{C}$, respectively.
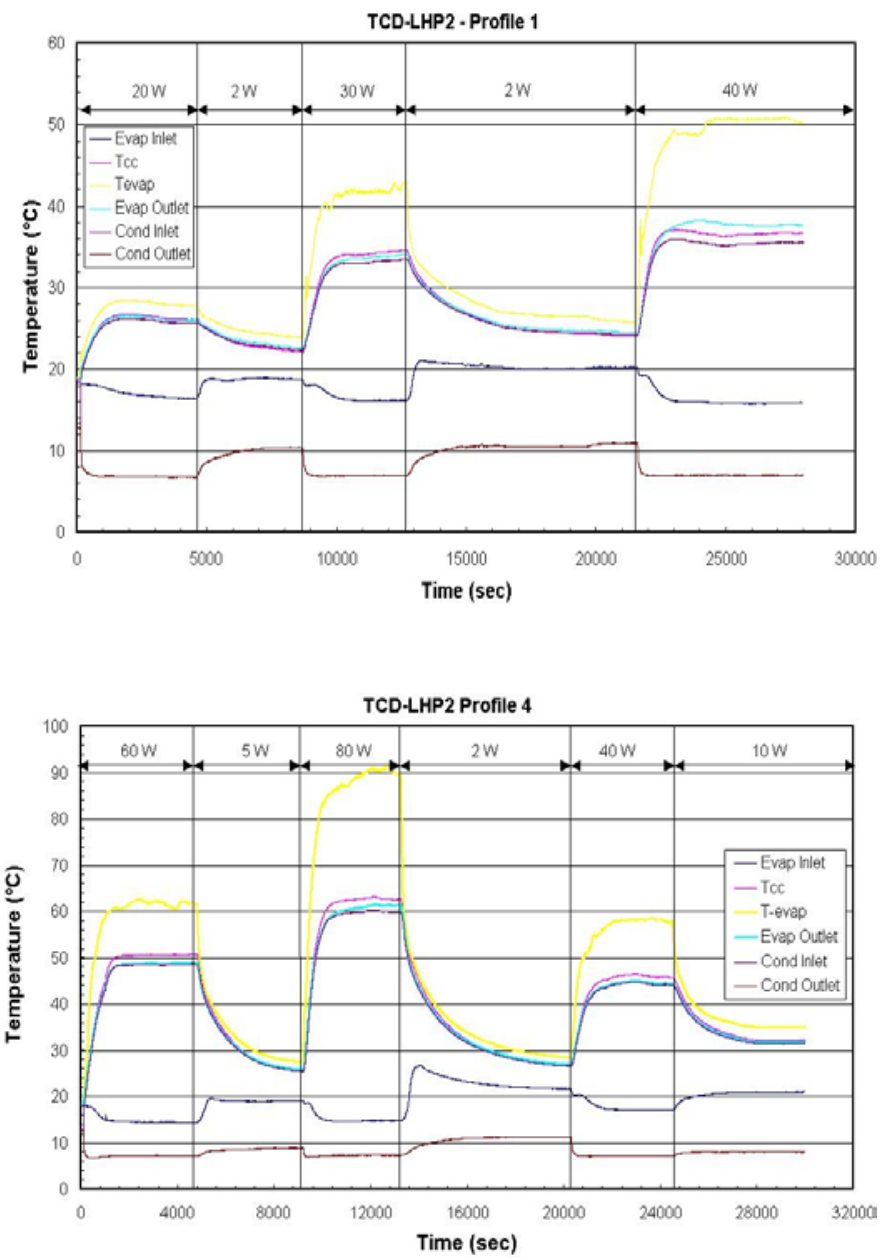

Figure 9. Power cycles for TCD-LHP2 - sink at $5^{\circ} \mathrm{C}$.

The results for the TCD-LHP2 show that the cold shock is not well noticed as when performing the thermal management with TCD-LHP. This may be explained by the fact that capillary evaporator and $\mathrm{CC}$ have the same outer diameters and the rapid increase on the heat load can cause a dryout of the wick structure. On the same way, as the flow rates are small, in this configuration the sub-cooled liquid that returns to the evaporator does not cause the temperature drop observed when the TCDLHP was operating. As the TCD-LHP2 thermal resistances are reduced, their influence on the overall device's performance contributes to minimize the cold shock phenomena.

In any circumstances, the TCD-LHP2 also showed reliable operation for the purposes that was designed for, even when considering the use of acetone. As the experimental tests were repeated over the time, the NCG influence did not present to be an issue as the temperature variations were always within the thermocouples deviations. However, investigations on this matter are still undergoing.
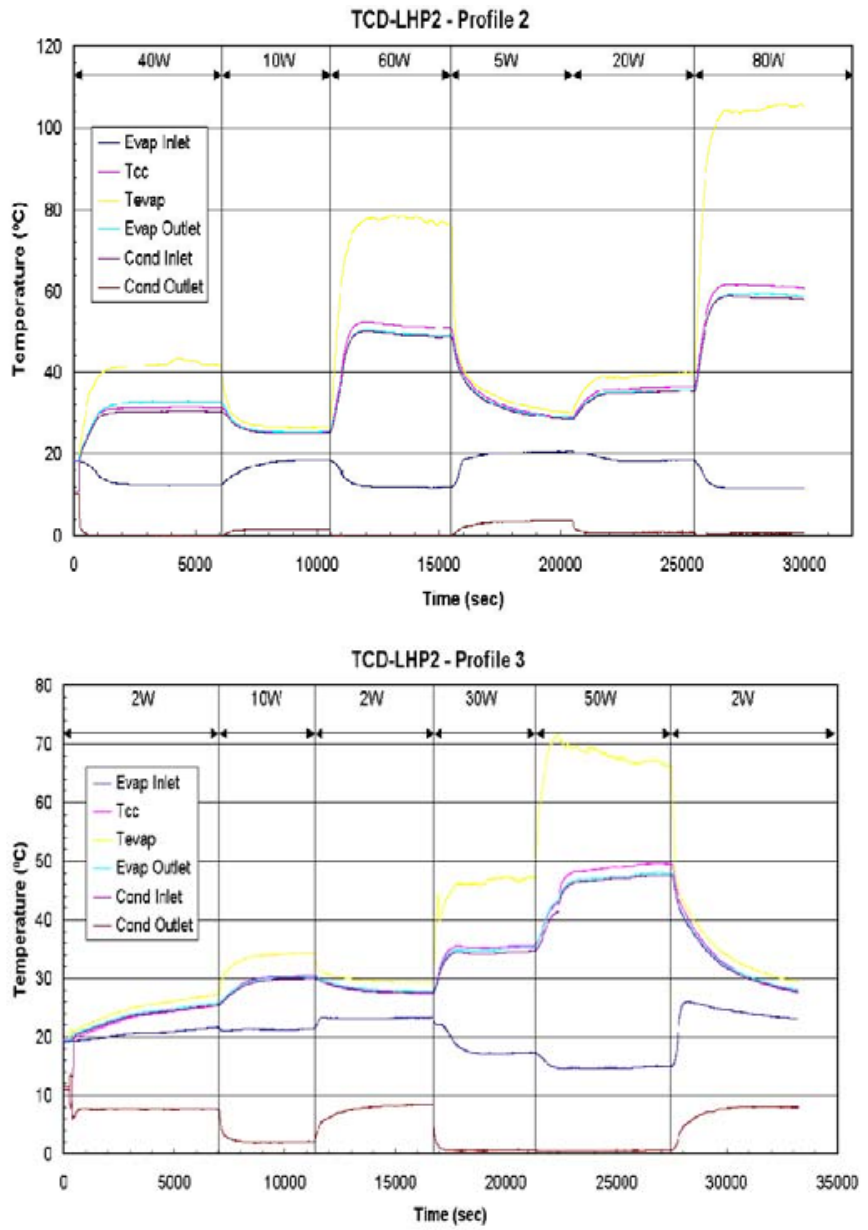

Figure 10. Power cycles for TCD-LHP2 - sink at $0^{\circ} \mathrm{C}$.

Just as observed during the previous tests, the TCDLHP2 also showed reliable operation at both low and high heat loads, specially when its operation at the sleeping mode is evaluated. Continuous heat transport was observed when the TCD-LHP2 was operating at profile 5 for both temperatures of the sink, as presented by Figs. 11 and 12 .

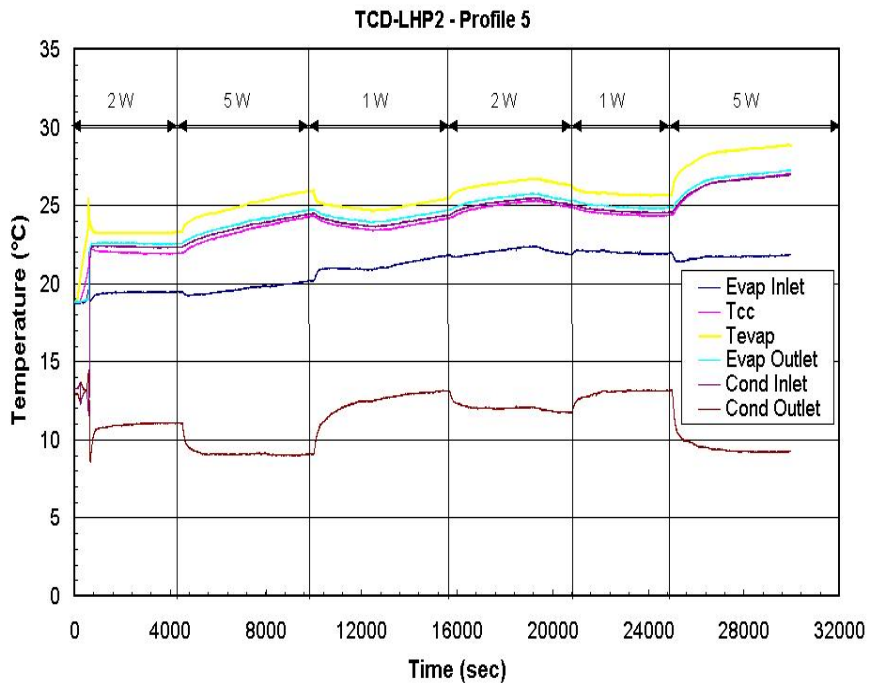

Figure 11. Sleeping mode operation - TCD-LHP2 and sink at $5^{\circ} \mathrm{C}$. 


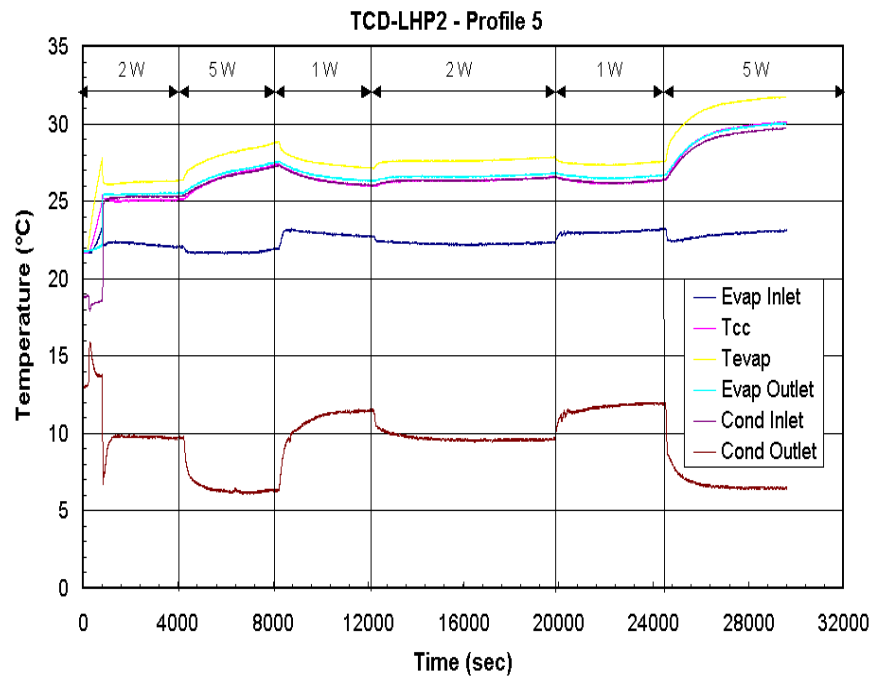

Figure 12. Sleeping mode operation - TCD-LHP2 and sink at $0^{\circ} \mathrm{C}$.

The overall results for the capillary evaporator temperature of TCD-LHP2 are presented by Fig. 13. It can be observed the higher temperatures verified during the tests when comparing the results with those presented in Fig. 8, showing the great influence that this configuration causes on the loop's thermal behavior.

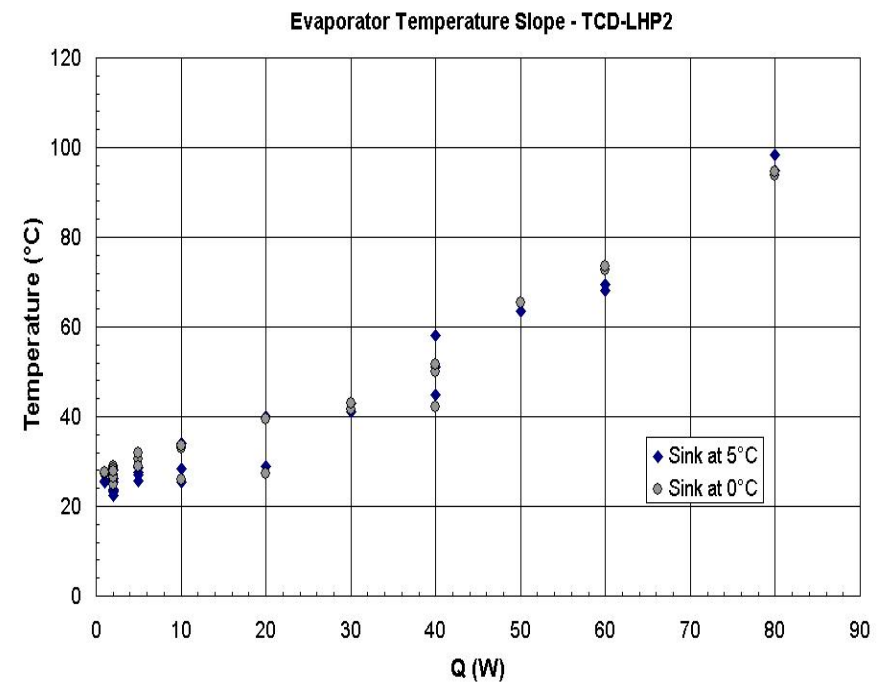

Figure 13. Overall evaporator temperatures for TCD-LHP2.

\section{THERMAL RESISTANCE INFLUENCE}

The experimental results presented different thermal resistances when comparing both LHPs and sink temperatures tested, as greater values were found for the TCD-LHP2. The thermal resistance is calculated as

$$
R_{T}=\left(T_{\text {evap }}-T_{C C}\right) / \dot{Q}
$$

with deviation of $\pm 5 \%$ and represents the resistances between the capillary evaporator and the CC.
The thermal resistance differences presented by Fig. 14 are mainly due to the reduced heat leak (heat transfer from the evaporator to the CC) that TCD-LHP presents when compared to TCD-LHP2. As the first one presents a CC with greater diameter and a geometric transition from the evaporator, then greater thermal resistances are found. Also, in this configuration, there is a greater presence of liquid in the evaporator core and as the liquid in the CC applies a static pressure (also better for the startup), the heat transfer is basically by conduction through the case and is relatively small resulting in greater thermal resistances [10]. This parameter also affects the liquid/vapor interfaces in the capillary evaporator, CC and condenser [11] directly reflecting on the operation temperature.

For the TCD-LHP2, as the geometric transition from the capillary evaporator to the CC does not exist, less thermal resistances are present. On the same way, as in this configuration the evaporator core presents both liquid and vapor phases (critical situation for the startup), then heat is transferred from the evaporator to the CC increasing the heat leak [10]. This represents that reduced values of thermal resistances are found for theTCD-LHP2 when compared to the TCD-LHP directly influencing the operation temperature.

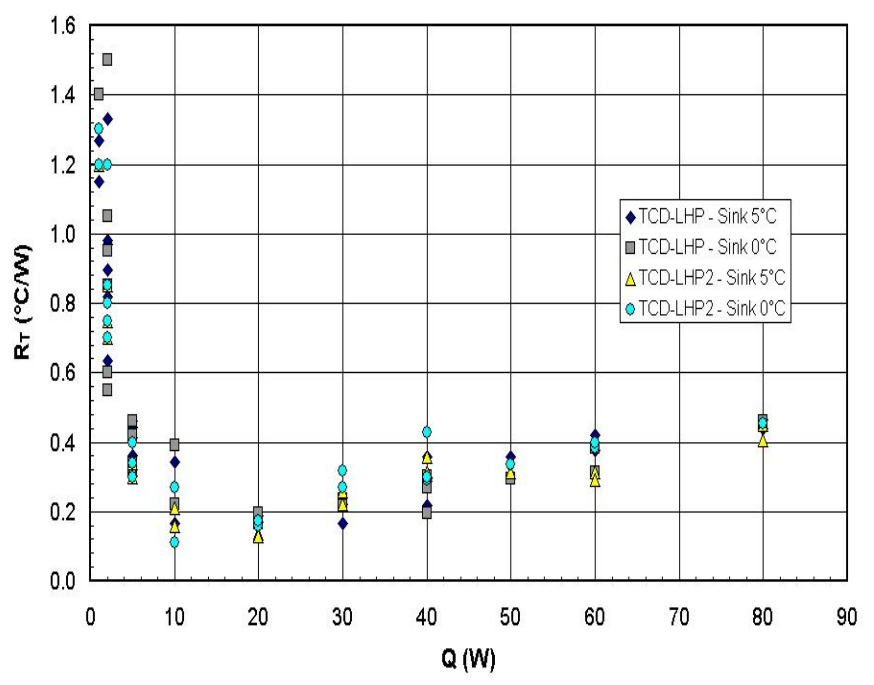

Figure 14. Thermal resistances for both LHPs and sink temperatures.

The heat leak can be estimated using the following energy balance

$$
\dot{Q}-\dot{Q}_{l e a k}=\dot{m} i_{l v}
$$

where the latent heat of vaporization $\left(i_{l v}\right)$ is taken at the working fluid saturation temperature of the evaporator and CC. The influence of the heat leak shows that it directly affects the operation temperatures during the LHP operation. As more liquid is present in the evaporator core, smaller heat leak will occur resulting in greater thermal resistances. When vapor is more present in the evaporator core, smaller thermal 
resistances are found resulting in greater heat leak from the evaporator to the $\mathrm{CC}$. The correct calculation of the heat leak is a difficult task to be done as this involves many other parameters like the heat transfer process and flow dynamics in the capillary evaporator liquid core and porous structures, etc. However, this parameter is interesting to be analyzed as it can be used to improve the design in order to have smaller operation temperatures with configurations like TCD-LHP2.

The life tests have shown the reliable behavior that both small-scale LHPs presented while performing the heat management. However, as the compensation chamber geometric configuration plays an important role in the devices' operation, careful attention must be paid in order to select the appropriate geometry. When using a CC with the same outer diameter as the capillary evaporator, a geometric transition can be present (similar to that on the TCD-LHP) so the thermal resistances can be increased and thus the operation temperatures would be reduced. This would greatly improve the LHP performance as lower evaporator and operation temperatures would be achieved, which contributes for the better control of the heat source temperature. The application of other materials as primary wick structures as mentioned above is also expected to contribute to improve the LHPs performance.

\section{CONCLUSION}

This paper presented the results of two small-scale LHPs that have been undergoing life tests under laboratory conditions for the past 20 months. Both LHPs were built to perform the thermal management of up to $100 \mathrm{~W}$ using acetone as the working fluid. This fluid has been selected as an option instead of ammonia in order to qualify it for future space missions as it represents less hazard and less expensive systems for distillation, purification and charging. The experimental results have shown the reliable operation of both LHPs under different sink temperatures and power cycles tested as they present acceptable operation with heat loads ranging from 1 to $80 \mathrm{~W}$.

The TCD-LHP2 presented higher evaporator temperatures and reduced thermal resistances when compared to the TCD-LHP as the set capillary evaporator/CC presents the same outer diameter and the presence of both liquid and vapor phases in the evaporator core. This factor plays an important role in the heat transfer process that directly affects the thermal resistance and thus the operation and evaporator temperature. Such a behavior also resulted in higher temperatures throughout the TCD-LHP2. The TCD-LHP presented more clearly the cold shock behavior when higher power was applied to the capillary evaporator and indication of vapor in the liquid line was noticed. When testing the TCD-LHP2, this behavior was not so intense probably due to its geometric characteristics.

The operation of both LHPs presented to be in accordance to their design parameters and show great potential to be used in space as they presented acceptable operation and the NCG influence has not presented to be an issue. When repeating the tests to compare the data, the temperature variations were always within the thermocouples deviation. Proper evaluation regarding the NCG generation is undergoing and will be discussed in a future report. Further accelerated life tests and qualification procedures are scheduled to be performed in the near future.

\section{ACKNOWLEDGMENTS}

This work has been supported by Fundação de Amparo a Pesquisa no Estado de São Paulo (FAPESP/Brazil), grants 03/08365-6 and 03/11477-0.

\section{REFERENCES}

1. Pauken, M. T., Birur, G., Nikitkin, M., Al-Khabbaz, F., "Thermal Performance Evaluation of a Small Loop Heat Pipe for Space Applications", International Conference on Environmental Systems - ICES, July 7-10, 2003, Vancouver, CA, paper 2003-01-2688.

2. Goncharov, K., Kolesnikov, V., "Development of Propylene LHP for Spacecraft Thermal Control", Proceedings of the $12^{\text {th }}$ International Heat Pipe Conference, Moscow-Kostroma-Moscow, Russia, 19-24 May, 2002, pp. 171-176.

3. Riehl, R. R., Dutra, T., "Development of an Experimental Loop Heat Pipe for Application in Future Space Missions", Applied Thermal Engineering No. 25, 2005, pp. 101-112.

4. Ku, J., Rogers, P., Cheung, K., "Investigation of Low Power Operation in a Loop Heat Pipe", $31^{\text {st }}$ International Conference on Environmental Systems, Orlando, FL, July 9-12, 2001, paper \# 2001-01-2192.

5. Watson, H., Gerhart, C., Mulholland, G., Gluck, D., "Steady-state Operation of a Loop Heat Pipe with Analytical Prediction", ASME Heat Transfer Division, Vol. 366-4, 2000, pp. 457-462.

6. Po-Ya A. Chuang, "An Improved Steady-State Model of Loop Heat Pipes Based on Experimental and Theoretical Analysis", PhD Dissertation, Department of Mechanical and Nuclear Engineering, Pennsylvania State University, PA, USA, 2003, 270p.

7. Riehl, R. R., "Comparing the Behavior of a Loop Heat Pipe with Different Inclinations of the Capillary Evaporator", $34^{\text {th }}$ International Conference on Environmental Systems, Colorado Springs, CO, July 19-22, 2004, paper \#2004-01-2510.

8. Ku, J., "Thermal Performance of Capillary Pumped Loops Onboard Terra Spacecraft", $34^{\text {th }}$ International Conference on Environmental Systems, July 19-22, Colorado Springs, CO, 2004, paper \# 2004-01-2504.

9. Nikitikin, M. N., Bienert, W. B., "High Power Cold Shock Phenomena in Loop Heat Pipes", AIP Conference Proceedings 552(1) 283-291, 2001.

10. Rogers, T. D., Perez, J., Ku, J., Kobel, M., Ochterbeck, J., Nelson, D., "Loop Heat Pipe Operating Temperature Dependence on Liquid Line 
Return Temperature" $34^{\text {th }}$ International Conference on Environmental Systems, July 19-22, Colorado Springs, 2004, CO, paper \# 2004-01-2506.

11. Vlassov, V. V., Riehl, R. R., "Modeling of Loop Heat Pipe for Ground and Space Conditions", $35^{\text {th }}$ International Conference of Environmental Systems, Rome, Italy, July 11-14, 2005, paper \# 05ICES-48.

\section{CONTACT}

Roger R. Riehl

National Institute for Space Research

Space Mechanics and Control Division

INPE-DMC/Satelite

Av. Dos Astronautas 1758, 12227-010

Sao Jose dos Campos, SP - Brazil

Phone: 5512 3945-6178 / Fax: 5512 3945-6226

E-Mail: rriehl@dem.inpe.br

\section{DEFINITIONS, ACRONYMS, ABBREVIATIONS}

$i_{l v} \quad$ Latent heat of vaporization $(\mathrm{J} / \mathrm{kg})$

$\dot{Q} \quad$ Heat load to the capillary evaporator (W)

$\dot{Q}_{\text {leak }} \quad$ Heat leak (W)

$\dot{m} \quad$ Working fluid mass flow rate $(\mathrm{kg} / \mathrm{s})$

$R_{T} \quad$ Thermal resistance $\left({ }^{\circ} \mathrm{C} / \mathrm{W}\right)$

$T_{\text {CC }} \quad$ Compensation chamber temperature $\left({ }^{\circ} \mathrm{C}\right)$

$T_{\text {evap }} \quad$ Evaporator temperature $\left({ }^{\circ} \mathrm{C}\right)$ 